\title{
DIFERENTES DIMENSÕES DA EDUCAÇÃO AMBIENTAL PARA A INSERÇÃO SOCIAL DOS PARQUES
}

\author{
Douglas de Souza Pimentel ${ }^{1}$ \\ Teresa Cristina Magro²
}

\section{Resumo}

A realização de educação ambiental (EA) é legalmente prevista para todas as Unidades de Conservação brasileiras. Assim, o objetivo do presente texto é analisar as suas diferentes dimensões, focando na construção do papel social dos parques. A gestão desses lida com a emergência dos problemas ligados às relações da administração com as pessoas. Nesse sentido, a EA é reduzida à mitigação dos impactos da visitação. Espera-se, mais amplamente, que a EA possa capacitar os membros comunitários a participação mais balizada nos conselhos consultivos. Deve ser pensada, portanto, sob diferentes objetivos como um instrumento importante para viabilizar a inserção social dos parques.

Palavras chave: Educação ambiental; Parques; Inserção social

\begin{abstract}
The implementation of environmental education (EE) is law for all protected areas in Brazil. The objective of this paper is to analyze its various dimensions, focusing on building the social role of the parks. The management of these deals with the emergence of problems connected with the administration's relations with people. In this sense, EA is reduced to mitigate the impacts of visitation. It is hoped, more broadly, that EA can empower community members to participate more focused on the advisory boards. It should be thought, therefore, under different objectives as an important tool to facilitate the social integration of parks.
\end{abstract}

Keywords: Environmental education, Parks, Social insertion

\section{Introdução}

O uso dos recursos naturais representa uma das principais discussões relacionadas às Unidades de Conservação (UCs). No caso dos parques, como áreas de Proteção Integral, o foco principal é a conservação dos ecossistemas. $\mathrm{O}$ uso indireto dos recursos é permitido, relacionando-se genericamente com a sua visitação e, especificamente, com projetos e políticas que fomentem formas de uso público mais planejado, envolvendo o ecoturismo e a

\footnotetext{
${ }^{1}$ Docente da Faculdade de Formação de Professores da UERJ e do Departamento de Geografia da UFF. E-mail: douglasgeia@gmail.com

${ }^{2}$ Engenheira Florestal e docente do Departamento de Engenharia Florestal da ESALQ/USP.

E-mail: teresa.magro@usp.br
} 
pesquisa. A educação ambiental, por sua vez, é uma vertente integradora do uso público, pois representa uma atividade prevista pela lei do SNUC para os parques (BRASIL, 2002), bem como para todas as UCs, frequentemente relacionada como uma ferramenta viabilizadora da gestão dessas atividades, pois parte-se da premissa que a mitigação e administração dos impactos nessas áreas protegidas dependem de um público usuário mais informado, um Conselho Gestor capacitado e a realização de pesquisas que permitam o seu monitoramento sócio ambiental. Também, a educação ambiental entendida como um processo de médio e longo prazo se viabiliza com programas específicos dentro das unidades de conservação, sejam elas de proteção integral ou uso sustentável.

O objetivo do presente texto é analisar as diferentes dimensões da educação ambiental em parques, focando na construção do papel social dessa categoria de UC, por intermédio de atividades de uso público.

\section{A Educação Ambiental como ferramenta para a inserção social dos parques}

No Brasil, o processo de discussão sobre educação ambiental começa a partir da década de 1970, porém só ganha maior dimensão pública na década de 1980, consolidando-se na Constituição Federal de 1988, que estabeleceu a promoção da educação ambiental como competência do Poder Público. O PRONEA (Programa Nacional de Educação Ambiental), de 1994, visou a consolidação do tema como uma política pública. Como resultado, tem-se o estabelecimento dos Parâmetros Curriculares Nacionais de 1996, em que o meio ambiente é colocado como um tema transversal às diferentes disciplinas. Em 1999 é publicada a lei que institui a Política Nacional de Educação Ambiental (PNEA) que reforça a visão desse processo educativo acontecendo de forma articulada em caráter formal e não formal (LOUREIRO, 2004; LOUREIRO et al., 2005). No entanto, a regulamentação dessa lei somente acontece em 2002, quando é definido o órgão gestor da PNEA. Além disso, a necessária articulação interministerial e o retorno de informações balizadas por pesquisa social das ações já implementadas ainda são insipientes (VASCONCELLOS, 2006).

Assim, os parques podem servir como lócus das ações de consolidação da Política de Educação Ambiental, pois: (1) representam um eixo de integração básico entre as ações do Ministério do Meio Ambiente e Ministério da Educação; (2) têm como premissa básica o uso público qualificado pela aquisição de conhecimentos e habilidades, reaproximando as pessoas dos ambientes naturais pela afetividade e reflexão sobre como suas ações o afetam; (3) permitem uma visão prática e crítica das relações da sociedade com a natureza de uma maneira geral e especificamente confrontando as noções de desenvolvimento sustentável e ecoturismo; (4) abarcam os discursos dicotômicos das relações entre ambiente e cultura, no campo das ações construídas socialmente, bem como, (5) necessitam ganhar significado para a sociedade e a Educação Ambiental, enquanto uma prática social, pode contribuir para tal se fomentar a integração participativa e democrática nas decisões sobre a gestão dos parques. 


\section{A Educação Ambiental para a gestão democrática de parques}

O SNUC incentiva a participação popular na criação e gestão de áreas protegidas. Para tal, há o reconhecimento de que a educação ambiental é um componente importante do processo, principalmente no estímulo a uma atuação cidadã (BRASIL, 2004). Dessa maneira, os Conselhos Gestores representam um espaço privilegiado para a democratização das relações entre os parques e a sociedade (IRVING et al., 2006; LOUREIRO et al., 2005).

A educação ambiental, enquanto um fenômeno social envolve diferentes atores com visões distintas sobre as relações entre a sociedade e natureza e com assimetrias de poder que resultam em diferentes processos, classificados por Loureiro e colaboradores (2005) em dois grandes blocos: um conservador e superficial que supervaloriza as soluções tecnológicas e o conhecimento científico; o outro, emancipatório, entende as questões ambientais como resultado de processos históricos e sociais, valorizando a democracia e o diálogo na resolução dos conflitos ambientais. Assim, os autores classificam a educação ambiental como uma:

[...] práxis educativa e social que tem por finalidade a construção de valores, conceitos, habilidades e atitudes que possibilitem o entendimento da realidade de vida e a atuação lúcida e responsável de atores sociais individuais e coletivos, no meio ambiente. (p.15)

Considerando a visão da Educação capaz de mediar interesses e conflitos, que promove a percepção crítica e histórica das diferentes facetas dos problemas ambientais, bem como a capacidade de uso desse conhecimento para a tomada de decisões e construção de estratégias coletivas (IBASE, 2006; LOUREIRO, 2004; LOUREIRO et al., 2005).

Assim, a educação ambiental é vista como um instrumento para disponibilizar informações, compartilhar percepções e ampliar o diálogo e ações conjuntas para fomento da atuação democrática e qualificada dos cidadãos nos Conselhos Gestores, pois nesse espaço decisório se manifestam as tensões entre a territorialidade local e a ação política do Estado. Os conflitos inerentes ao processo são, dessa maneira, explicitados, ampliam qualitativamente as discussões e podem provocar mudanças positivas nas relações entre o parque e a sociedade (IBAMA, 2002; IBASE, 2006; LOUREIRO et al., 2005). Para tal, é necessário o desenvolvimento de mecanismos que promovam a efetiva participação das comunidades locais nos processos decisórios, mas também a formação de um cidadão pleno, com posturas cooperativas, ciente de seus direitos e deveres (PÁDUA; TABANEZ; SOUZA, 2003; ZIAKA; ROBICHON; SOUCHON, 2002). Nesse sentido, a educação ambiental é entendida como prática transformadora da realidade social e também construída por ela, em um processo dialógico, crítico e que depende da interação entre diferentes atores para a definição política do espaço e destinos (LOUREIRO et al., 2005; LOUREIRO, 2006).

No entanto, essa prática também teria que ser construída nos órgãos gestores nas diferentes esferas do poder público, pois ainda se podem identificar resquícios de um 
pensamento de controle mais centralizado desses espaços reservados. Esse enfatiza a visão de separação entre natureza e sociedade e consequentemente, entre a gestão estritamente baseada nos preceitos ecológicos e a concessão de espaços democráticos de decisão (LOUREIRO; AZAZIEL; FRANCA, 2007). Esses entraves podem ser superados no âmbito do Conselho Gestor uma vez que processos da educação ambiental podem catalisar a construção de legitimidade e representatividade, condições estas básicas para a efetiva intervenção política da comunidade na gestão dos parques.

A educação ambiental pode ser considerada a porta que abriu várias possibilidades no cenário onde o uso público é inserido nas Unidades de Conservação. Abrange potencial para categorias de uso restrito como as Estações Ecológicas e Reservas Biológicas permeando categorias menos restritivas que potencializam atividades mais ligadas ao lazer como o turismo em meio natural e o ecoturismo.

\section{Ecoturismo e Educação Ambiental: contribuindo para a construção de posturas ambientalmente responsáveis}

O ecoturismo é definido como uma vertente das atividades turísticas relacionadas à ambientes naturais e posturas de respeito ao meio ambiente e culturas locais (WESTERN, 1999). As áreas protegidas atraem o ecoturismo e frequentemente esse é observado nos parques (WEST; IGOE; BROCKINGTON, 2006). Porém, as atividades de turismo com base na natureza vêm crescendo de maneira significativa e trazem consigo alguns perigos que comprometem a sua própria definição. A primeira refere-se aos resultados do aumento da visitação e a forma como as atividades são desenvolvidas com consequentes impactos negativos ao meio ambiente e nas populações tradicionais (LEUZINGER, 2002; WEST; IGOE; BROCKINGTON, 2006).

Pode-se identificar assim, baseado nas diretrizes do WWF - World Wide Fund for Nature (Fundo Mundial para a Natureza), os pontos de congruência entre o ecoturismo, a conservação da natureza e a educação ambiental. Segundo BOO (1999), a aplicação desses conceitos na administração de parques e suas zonas de amortecimento, bem como a ampliação do poder das decisões políticas locais e supralocais pela construção de uma consciência crítica nos visitantes e comunidades por intermédio da Educação Ambiental, representam um impacto positivo catalisado pelo ecoturismo.

Takahashi (2004), no entanto, observa que no Brasil essa atividade encontra-se desordenada e direcionada meramente pelos interesses mercadológicos, o que comprometeria o alcance dos objetivos socioeconômicos e ambientais. As atividades de ecoturismo e educação ambiental poderiam ser consideradas como um investimento em longo prazo na conservação da área e premissa básica do papel do ecoturismo na proteção da biodiversidade (SILVA; COSTA NETO, 2007).

A educação ambiental pode também pode atuar na diminuição dos impactos negativos da visitação ao promover o seu planejamento e, ao criar maior consciência e apreço pelos recursos ambientais e culturais protegidos, bem como uma melhor compreensão dos objetivos 
das atividades de conservação, influenciar uma visão positiva sobre o parque e o órgão gestor (VASCONCELLOS, 2006). No entanto, as práticas de educação ambiental também são deficitárias nos parques. Os programas educativos são recentes e precisam ser ampliados e melhor compreendidos com a pesquisa e adequados para alcance dos objetivos, tanto sob o ponto de vista da gestão, quanto da efetiva promoção de mudança de comportamento perante a conservação dos ecossistemas. Além disso, a emergência das situações do manejo dos impactos da visitação, muitas vezes leva ao fechamento de algumas unidades de conservação e de trilhas. Essa atitude de manejo prejudica a construção de uma imagem positiva da UC em função dos conflitos entre a administração, comunidades e visitantes. Além disso, muitas vezes a educação ambiental fica limitada às práticas da interpretação ambiental (IA), essas, mais objetivas por estarem ligadas às demandas da recreação (VASCONCELLOS, 2006).

As atividades de educação ambiental devem se voltar também para fora dos parques, pois os conceitos relacionados a conservação ambiental são amplos e prescindem de mudanças mais profundas no indivíduo ou na sociedade que os programas desmembrados em objetivos pragmáticos não conseguem transpor. Assim, o ecoturismo aliado à educação ambiental deve estimular uma visão mais abrangente dos problemas ambientais, auxiliando na compreensão das variáveis sociais, econômicas e políticas envolvidas na complexidade ambiental, além de incentivar a participação individual e coletiva (SILVA; COSTA NETO, 2007; VASCONCELLOS, 2006). Além disso, essa aliança pode ajudar a ampliar a significação social dos parques, ao tornar as pessoas mais conscientes sobre a complexidade das questões ambientais (TAKAHASHI, 2004). Os parques, como locais inerentemente receptivos dessas atividades podem se constituir em centros irradiadores de novas posturas ambientalmente responsáveis. Logo, essas UCs, concebidas originalmente como locais de preservação da vida selvagem, são cada vez mais encaradas como a vanguarda das transformações sociais e econômicas, aumentando, porém, o grau de complexidade de sua gestão (BENSUSAN, 2006). Assim há necessidade de pesquisa na área sócio-ambiental para fomentar o órgão gestor de UCs com informações em campos multidisciplinares que permitam uma administração mais eficiente do seu uso público.

\section{A pesquisa: informações socioambientais qualificadas para subsidiar a educação ambiental}

Alguns biólogos defendem a supremacia das pesquisas ecológicas na determinação dos rumos das atividades de conservação. Assim, os resultados dessa pesquisa básica em parques, muitas vezes ficam restritos ao meio acadêmico e não sensibilizam o público. Além disso, a ciência ecológica, aplicada politicamente, pode conduzir a consensos acríticos e pouco práticos (LOUREIRO et al., 2005). Esses fatos podem estar relacionados com a perda de força política dos conhecimentos ecológicos básicos, alijados das questões sociais, em determinar os rumos da conservação no Brasil.

Em geral a pesquisa ecológica básica não abrange os processos socioambientais que determinam o alcance do objetivo primário dos parques. Porém, infelizmente ainda observase que a Educação Ambiental voltada para um caráter imediatista e restrito aos aspectos 
ecológicos dos espaços naturais (CASCINO, 2000; PÁDUA; TABANEZ; SOUZA, 2003). Buscar as bases da relação complexa entre natureza e sociedade também pode fomentar a construção de significado social para a pesquisa e para os parques. No entanto, os dados disponíveis, tanto na esfera biológica quanto social são escassos e não permitem uma avaliação acurada ao longo do tempo (NAUGHTON-TREVES; HOLLAND; BRANDON, 2005).

Coloca-se em evidência a importância da educação ambiental, pois essa, enquanto prática construída na sociedade pode ser instrumentalizada pela pesquisa básica e gerar conhecimento socialmente referenciado para a conservação em parques (SANTOS et al., 2000).

Sob o que foi exposto, a educação ambiental pode ser vista como mediadora da inserção social dos parques. Essa integra diferentes objetivos e atores em três princípios básicos: a capacitação de pessoas; a gestão da UC e a formação de consciência sobre o meio com conseqüente mudança de valores e atitudes (Figura 1).

Figura 1. A Educação Ambiental relacionada com a pesquisa e a inserção social dos parques, a partir de três princípios básicos encontrados na literatura

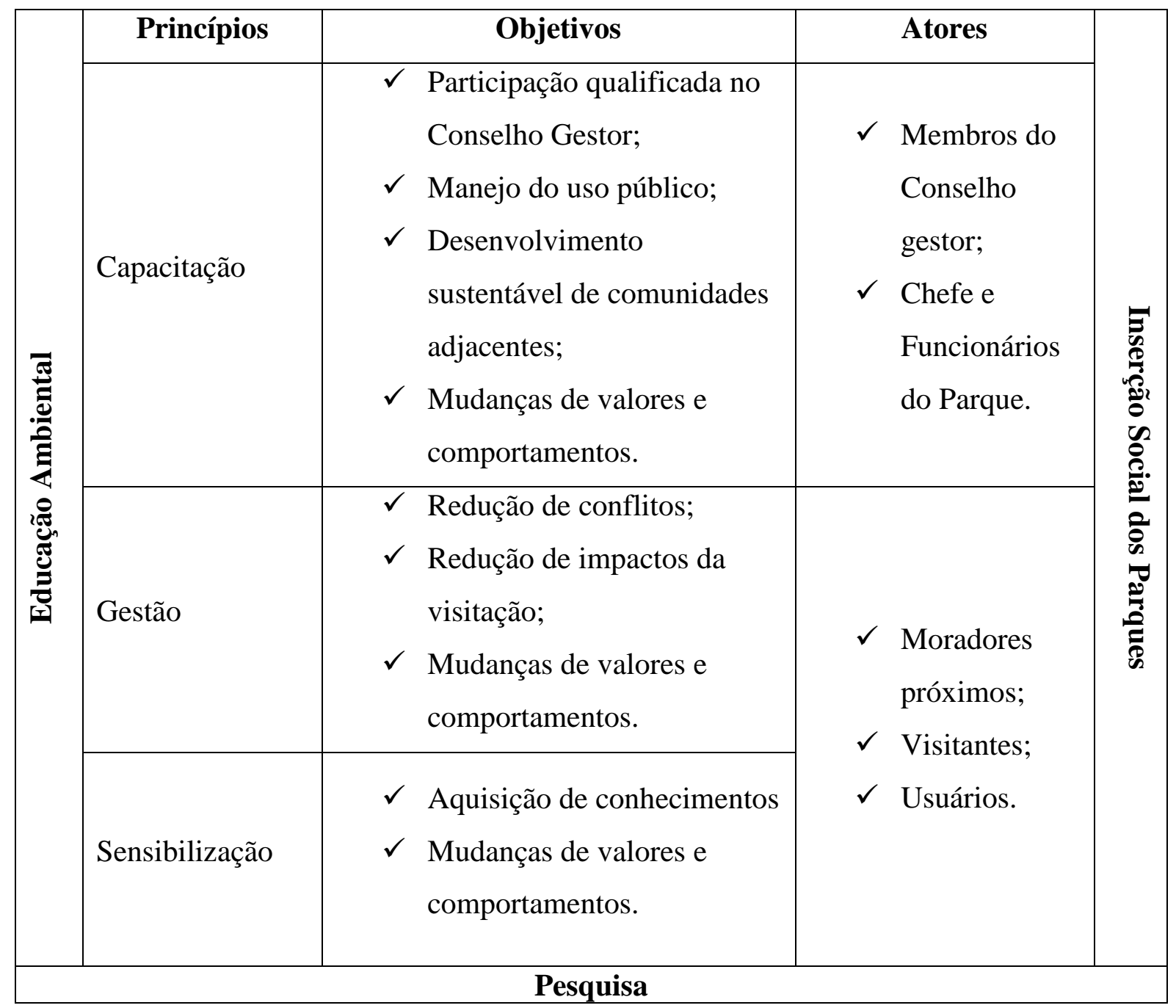




\section{Considerações finais}

Os parques podem ser encarados como laboratórios de ensino de uma nova postura social em relação ao meio ambiente. Daí a importância da educação ambiental nessas áreas, pois suas práticas, quando socialmente referenciadas, promovem uma visão crítica e interligam as atribuições básicas dessas UCs, relacionadas a conservação, ao seu uso público e ao desenvolvimento sustentável das comunidades adjacentes. No entanto, essas práticas não devem estar restritas aos aspectos internos da gestão das unidades de conservação. Fala-se, portanto, em uma educação ambiental composta por vários níveis, que tem como princípio básico à inserção dos parques na sociedade, pela conquista de significado social desse instrumento de conservação.

Porém, advoga-se também por uma nova postura da sociedade em relação o meio ambiente. Logo, essa não pode ficar restrita aos espaços reservados para a conservação da natureza. Os parques são importantes nesse momento de crise ambiental, mas uma atitude pró ativa requer uma avaliação sobre como podemos utilizá-los na formulação de uma nova ética social para a conservação. Isto é, eles têm valor per si na conservação da biodiversidade, no desenvolvimento de valores conservacionistas e por serem um dos mecanismos legais que definem socialmente a conservação. Porém, o seu valor não pode apenas restringir-se a isso. Assim, fica evidente um novo e importante papel social dos parques: a mediação na formação de cidadãos conscientes e com novas práticas frente às questões ambientais e sociais. Logo, a conservação deve transpor as cercas dos parques rompendo efetivamente o seu isolamento, pelo estabelecimento de políticas que tornem a conservação importante para a sociedade como um todo. Dessa forma se atinge a possibilidade de suporte político na tomada de decisões para projetos que possam afetar direta ou indiretamente o ambiente natural em médio e longo prazo.

\section{Referências Bibliográficas}

BENSUSAN, N. Conservação da biodiversidade em áreas protegidas. Rio de Janeiro: Ed. FGV, 2006. 176 p.

BOO, E. O planejamento ecoturístico para áreas protegidas. In: LINDBERG, K.; HAWKINS, D.E. (Ed.). Ecoturismo: um guia para planejamento e gestão. 2. ed. São Paulo: Ed. SENAC, 1999. cap. 1, p. 31-57.

BRASIL. Lei $\mathrm{n}^{\circ}$ 9.985, de 18 de julho de 2000. Institui o Sistema Nacional de Unidades de Conservação da Natureza SNUC. Brasília: IBAMA, Diretoria de Ecossistemas, 2002. 35 p.

BRASIL. Ministério do Meio Ambiente. Gestão Participativa do Sistema Nacional de Unidades de Conservação -SNUC. Brasília, 2004. 205 p.

CASCINO, F. Educação ambiental: princípios, história e formação de professores. São Paulo: Ed. SENAC, 2000. 109 p. 
INSTITUTO BRASILEIRO DE MEIO AMBIENTE E RECURSOS NATURAIS RENOVÁVEIS. Como o Ibama exerce a educação ambiental. Brasília, 2002. 32 p.

INSTITUTO BRASILEIRO DE ANÁLISES SOCIAIS E ECONÔMICAS. Educação ambiental em unidades de conservação. Rio de Janeiro, 2006. 28 p.

IRVING, M.A.; COZZOLINO, F.; FRAGELLI, C.; SANCHO, A. Construção de governança democrática: interpretando a gestão de parques nacionais no Brasil. In: IRVING, M.A. (Org.). Áreas Protegidas e inclusão social: construindo novos significados. Rio de Janeiro: Fundação Bio-Rio - Núcleo de produção Editorial Aquarius, 2006. p. 41-75.

LEUZINGER, C. Ecoturismo em parques nacionais: a compatibilidade entre a função de preservação ambiental e a prática do ecoturismo em parques nacionais. Brasília: W.D. Ambiental, 2002. 150 p.

LOUREIRO, C.F.B. Educação ambiental e gestão participativa na explicitação e resolução de conflitos. Gestão em Ação, Salvador, v. 7, n. 1, p. 1-16, jan./abr. 2004.

Crítica ao fetichismo da individualidade e aos dualismos na educação ambiental. Educar, Curitiba, n. 27, p. 37-53, 2006.

LOUREIRO, C.F.B.; AZAZIEL, M.; FRANCA, N.; BRASILEIRO, R.F.; MUSSI, S.M.; LAFFAILLE, T.M.S.; LEAL, W.O. Educação ambiental e gestão participativa em unidades de conservação. 2. ed. Rio de Janeiro: IBAMA, 2005. 57 p.

LOUREIRO, C.F.B.; AZAZIEL, M.; FRANCA, N. Educação ambiental e conselho em unidades de conservação: aspectos teóricos e metodológicos. Rio de Janeiro: Ibase, 2007. 87 p.

NAUGHTON-TREVES, L.; HOLLAND, M.B.; BRANDON, K. The role of protected areas in conserving biodiversity and sustaining local livelihoods. Annual Review of Environment and Resources, Palo Alto, v. 30, p. 219-252, 2005.

PÁDUA, S.M.; TABANEZ, M.F.; SOUZA, M.G. A abordagem participativa na educação para a conservação da natureza. In: CULLEN, JR., L. RUDRAN, R.; VALLADARESPÁDUA, C. (Org.). Métodos de estudos em biologia da conservação e manejo da vida silvestre. Curitiba: Universidade Federal do Paraná; Fundação O Boticário de Proteção à Natureza, 2003. p. 557-591.

SANTOS, J.E.; SATO, M.; PIRES, J.S.R.; MAROTI, P.S. Environmental education práxis toward a natural conservation area. Revista Brasileira de Biologia, São Carlos, v. 60, n. 3, p. 361-372, 2000.

SILVA, N.P.S.; COSTA NETO A.R. A educação ambiental como instrumento de sensibilização turística em unidades de conservação. 3. ed. Revista Eletrônica Aboré, Manaus, 2007. Disponível em: <http://www.revista.uea.edu.br/abore/comunicacao 
/comunicacao_pesq_3/Nathalin\%20Priscila\%20de\%20Souza\%20da\%20Silva.pdf $>$. Acesso em: 27 mar. 2008.

TAKAHASHI, L. Uso público em unidades de conservação. Cadernos de Conservação, Curitiba, v. 2, n. 2, 40 p. out. 2004.

TEIXEIRA, C. O desenvolvimento sustentável em unidade de conservação: a "naturalização" do social. Revista Brasileira de Ciências Sociais, São Paulo, v. 20, n. 59, p. 51-56, out. 2005 .

VASCONCELLOS, J.M. Educação e interpretação ambiental em unidades de conservação. Cadernos de Conservação, Curitiba, v. 3, n. 4, 86 p. dez. 2006.

WEST, P.; IGOE, J.; BROCKINGTON, D. Parks and people: the social impact of protected areas. Annual Review of Anthropology, Palo Alto, v. 35, p. 251-277, 2006.

WESTERN, D. Prefácio: definindo ecoturismo. In: LINDBERG, K.; HAWKINS, D.E. (Ed.). Ecoturismo: um guia para planejamento e gestão. 2. ed. São Paulo: Ed. SENAC, 1999. p.1322.

ZIAKA, Y; ROBICHON, P.; SOUCHON, C. Educacion ambiental: 6 propuestas para actuar como ciudadanos. Cuzco: Fundacíon Charles Léopold Mayer para el Progreso del Hombre; Centro de Estúdios Regionales Andinos Bertolomé de las Casas, 2002. 134 p. (Debate para otro futuro, 4; Serie Humanidad y Biósfera). 